\title{
Detección de anticuerpos contra Trypanosoma cruzi en Somoto, Nicaragua, mediante ELISA indirecto e IFI en muestras de sangre en papel de filtro
}

\author{
Xiomara Palacios, ${ }^{1}$ Alejandro Belli ${ }^{1}$ y Ana M. Espino ${ }^{2}$
}

RESUMEN Se estandarizó un inmunoensayo enzimático en fase sólida (ELISA) para estudiar la presencia de anticuerpos contra Trypanosoma cruzi en personas asintomáticas que viven en un área endémica de enfermedad de Chagas en Nicaragua. El ensayo fue estandarizado para el análisis de muestras de sangre colectadas en papel de filtro como método simple de transporte de muestras de sangre. Se realizó un estudio previo en el que se estudiaron por ELISA 18 muestras de suero total y 18 eluidos de sangre de pacientes con enfermedad de Chagas crónica, 30 muestras de suero y 30 eluidos de sangre de personas sanas que se utilizaron como controles negativos y 14 muestras de suero y 14 eluidos de sangre de pacientes con leishmaniasis cutánea o visceral que se utilizaron para los estudios de reacciones cruzadas. Tanto con el suero total como con los eluidos de sangre, la prueba de ELISA proporcionó una sensibilidad de $100 \%$ y una especificidad de 90\%; solo se observaron reacciones cruzadas con las muestras de pacientes con leishmaniasis visceral. El estudio poblacional incluyó a ocho comunidades rurales de Somoto, Nicaragua. Mediante un muestreo al azar se colectaron muestras de sangre en papel de filtro a 2434 personas (1 335 del sexo masculino y 1099 del sexo femenino) de las comunidades de Aguas Calientes, La Manzana, Los Canales, Santa Rosa, Las Playas, El Brocal, Santa Isabel y Santa Teresa. Las muestras fueron estudiadas por ELISA e inmunofluorescencia indirecta (IFI) encontrándose un total de 260 seropositivos por ELISA (10,7\%), 207 de los cuales fueron también positivos por IFI (8,5\%). La mayoría de los sueros seropositivos correspondieron a personas del sexo femenino con ambas técnicas, pero la diferencia entre hombres y mujeres no fue estadísticamente significativa. Los resultados obtenidos con ambas técnicas mostraron una excelente concordancia. Con respecto a la edad se observó una curva ascendente, con 5,4\% de seropositivos por ELISA en individuos de 0-10 años y 42,7\% en mayores de 50 años. La vasta mayoría de los individuos analizados fueron asintomáticos.

La infección humana por Trypanosoma cruzi, agente causal de la en-

\footnotetext{
1 Dirección de Parasitología, Centro Nacional de Diagnóstico y Referencia, Managua, Nicaragua.

2 Departamento de Parasitología, Instituto de Medicina Tropical "Pedro Kourí". Toda la correspondencia debe ser enviada a Ana M. Espino a la siguiente dirección postal: Instituto de Medicina Tropical "Pedro Kourí", Apartado 601, Zona 13, Ciudad Habana, Cuba. Fax: (53-7) 246051. Correo electrónico: amespino@ipk.sld.cu
}

fermedad de Chagas, es altamente prevalente en muchos países de Centroamérica y Sudamérica. Según estimaciones de la Organización Panamericana de la Salud/Organización Mundial de la Salud (OPS/OMS), 16 a 18 millones de personas están actualmente infectadas y 100 millones se encuentran en riesgo de contraer la enfermedad (1, 2). En Nicaragua, la dis- tribución de la enfermedad de Chagas depende directamente de la dispersión de sus principales vectores, Rhodnius prolixus y Triatoma dimidiata. Estudios anteriores han demostrado la presencia de estos vectores, junto a otros elementos de la cadena epidemiológica, en diferentes regiones $(3,4)$, lo cual sugiere que la enfermedad podría estar ampliamente distribuida en todo el 
país. Según Schofield y Dujardin (5) en Nicaragua podrían presentar anticuerpos contra T. cruzi 67000 personas, pero, debido al escaso número de estudios epidemiológicos realizados, sigue sin definir la verdadera magnitud de este importante problema de salud.

La enfermedad de Chagas es transmitida fundamentalmente por vectores (Triatominae) (6) y transfusiones de sangre infectada (7), y su diagnóstico de certeza solo es posible mediante la observación microscópica del parásito en las muestras de sangre del individuo parasitado o a través de métodos parasitológicos como el xenodiagnóstico y el hemocultivo (8). Estos métodos, además de difíciles y laboriosos, solo son útiles en la fase aguda de la enfermedad, ya que en la fase crónica la parasitemia desaparece y, en consecuencia, solo se obtienen resultados positivos en aproximadamente la mitad de los pacientes $(8,9)$. Por este motivo, el inmunodiagnóstico basado en la detección de anticuerpos contra $T$. cruzi mediante hemaglutinación indirecta (HAI), inmunofluorescencia indirecta (IFI) o inmunoensayo enzimático (ELISA) en fase sólida (9-11), o en la demostración de la presencia de antígenos por medio de la determinación de anticuerpos líticos (12), ha sido generalmente aceptado como criterio de infección.

Según nuestro conocimiento, la región más afectada por la enfermedad de Chagas en Nicaragua es la Zona Norte, en particular la región de Somoto, donde la presencia de la enfermedad se confirmó por primera vez en 1965 (13). Somoto, en la frontera con Honduras, es una región montañosa y boscosa de clima tropical, ubicada a $600 \mathrm{~m}$ sobre el nivel del mar. Su población, con un nivel socioeconómico muy bajo, vive básicamente de la agricultura y en su mayoría las viviendas son construcciones de barro, madera y hojas de palma o combinaciones de estos materiales, con pisos de tierra. Habitualmente, conviven con las personas o muy cerca de ellas diferentes animales domésticos que sirven de reservorio a T. cruzi, tales como perros y gatos, lo cual contribuye a la transmisión de la enfermedad.
La infraestructura de salud de $\mathrm{Ni}$ caragua es deficiente para hacer el diagnóstico de la enfermedad de Chagas, pues son muy pocos los centros hospitalarios que disponen de técnicas serológicas y de personal debidamente capacitado. Además de los laboratorios de la Cruz Roja Internacional, que tienen a su cargo la investigación de la mayor parte de las donaciones de sangre, el Centro Nacional de Diagnóstico y Referencia (CNDR) de Managua es la única institución potencialmente capaz de asumir el diagnóstico serológico de la enfermedad de Chagas, puesto que posee un equipamiento adecuado y personal técnico con adiestramiento en técnicas de diagnóstico. Sin embargo, hasta el momento el CNDR solo disponía de la técnica de IFI para el diagnóstico de esta enfermedad. Con el propósito de incrementar el potencial diagnóstico del CNDR y establecer una técnica altamente sensible que permita estudiar muchas muestras al mismo tiempo, en el presente estudio nos propusimos los siguientes objetivos: 1) estandarizar una prueba de ELISA para el estudio de muestras de sangre recolectadas en papel de filtro y demostrar que la sensibilidad y la especificidad del diagnóstico no varían utilizando suero completo y eluidos de sangre recogida en papel de filtro; 2) emplear la prueba de ELISA con muestras recolectadas en papel de filtro en un estudio poblacional con el propósito de detectar la presencia de anticuerpos contra $T$. cruzi en ocho comunidades de la región de Somoto, y 3) comparar la sensibilidad y especificidad diagnóstica de esta prueba con las de la IFI.

\section{MATERIALES Y MÉTODOS}

El estudio fue dividido en dos etapas. En la primera se estandarizó una prueba de ELISA indirecta empleando como antígeno un extracto crudo de epimastigotes de $T$. cruzi preparado por exposición a ultrasonidos (3 ciclos de 1 minuto a $18 \mathrm{KHz}$, a intervalos de 30 segundos) y centrifugación a 12000 g durante 1 hora a $4{ }^{\circ} \mathrm{C}$ (14). El procedimiento para la realización de la prueba de ELISA fue semejante al utilizado por otros autores $(15,16)$, pero se utilizaron placas de poliestireno de 96 pocillos de fondo plano (NUNC, Rochester, NY) sensibilizadas con $10 \mu \mathrm{g} / \mathrm{mL}$ del antígeno de T. cruzi, una anti-IgG humana marcada con peroxidasa (Sigma Chemical Co., Inc., Milwaukee, WI) a la dilución 1:5 000, como conjugado, y o-fenilendiamina como sustrato. Se determinaron las absorbencias a $492 \mathrm{~nm}$ mediante un lector de microELISA (Organon, West Orange, NJ).

Para estandarizar la prueba de ELISA, a 18 pacientes con enfermedad de Chagas en fase crónica se les extrajo una muestra de sangre venosa, de la cual se separó el suero, y otra por punción del dedo índice, que se recogió en papel de filtro. La información sobre estos pacientes se obtuvo a partir de las historias clínicas del hospital "La Mascota", de Managua; todos procedían de áreas donde la enfermedad de Chagas es endémica y habían estado expuestos a la picadura del vector durante muchos años, presentaban títulos elevados de anticuerpos por IFI ( $\geq 1: 1024)$ y HAI $(\geq 1: 250)$, porcentajes de lisis mediada por complemento superiores a $20 \%$, y alteraciones electrocardiográficas (arritmia y bradicardia, entre otras) que sugerían infección crónica por T. cruzi. También se extrajo sangre venosa, que fue recolectada en papel de filtro, a 30 personas sanas que habían realizado donaciones de sangre dos semanas antes del inicio del estudio; todas habían sido consideradas negativas a la enfermedad de Chagas por el Banco de Sangre de la Cruz Roja Internacional de Managua, y también habían sido negativas en la IFI y habían referido no haber padecido malaria, leishmaniasis $u$ otra enfermedad relacionada, por lo que fueron utilizados como controles negativos. Adicionalmente, para los estudios de reacción cruzada se recolectaron muestras de sangre de 4 pacientes con leishmaniasis visceral y de 10 con leishmaniasis cutánea ingresados en el hospital "La Mascota".

Las muestras de sangre extraídas mediante punción del borde externo del dedo índice a cada paciente y per- 
sona sana fueron colocadas sobre dos círculos de papel de filtro (Whatman No. 1, Whatman International Ltd., Maidstone, Kent, Reino Unido) de 0,6 cm de diámetro (17), los cuales, una vez impregnados de sangre, se dejaron secar a temperatura ambiente, fueron identificados con el nombre del individuo, empaquetados en sobres de nailon con sílica para prevenir la humedad y guardados a $4{ }^{\circ} \mathrm{C}$ hasta su estudio. Para las pruebas serológicas cada círculo de papel fue colocado en el fondo de una placa de microtitulación, se le añadieron $100 \mu \mathrm{L}$ de solución salina tamponada con fosfato (PBS) 0,01 mol/L, pH 7,2 y se incubó durante toda la noche a $4{ }^{\circ} \mathrm{C}$. Al día siguiente se recolectó el eluido y se estudó por ELISA e IFI. Los sueros fueron estudiados por ELISA a diluciones dobles desde 1:200 hasta 1:1600 y los eluidos a diluciones dobles desde 1:5 hasta 1:40. Se seleccionó como óptima la dilución de suero y eluido de sangre con la cual la absorbencia de los pacientes con enfermedad de Chagas crónica fuera igual o mayor a cinco veces la media de la absorbencia de las muestras negativas. Se consideró positiva toda muestra cuya absorbencia fuera mayor que la absorbencia media de los negativos \pm 2 desviaciones estándar (14). Cada muestra de suero y eluido de sangre fue estudiada por ELISA, por duplicado, y el resultado se expresó como la absorbencia media de ambas determinaciones. Se aplicó la $t$ de Student para comparar las absorbencias medias de los controles negativos, de los pacientes con enfermedad de Chagas en fase crónica y de los pacientes con leishmaniasis visceral y cutánea. Para calcular la sensibilidad y especificidad de la prueba de ELISA con suero total y eluidos de sangre se tomaron como referencia los datos clínicos, epidemiológicos y serológicos recopilados de las historias clínicas de los pacientes con enfermedad de Chagas crónica.

La segunda etapa del trabajo consistió en realizar un estudio poblacional en ocho comunidades de Somoto, seleccionadas al azar, en las cuales se recolectaron muestras de sangre en papel de filtro a 2434 personas que fue- ron estudiadas mediante ELISA e IFI. Las comunidades estudiadas fueron: Aguas Calientes, con 99 casas y 381 habitantes; La Manzana, con 96 casas y 542 habitantes; Los Canales, con 108 casas y 593 habitantes; Santa Rosa, con 66 casas y 324 habitantes; Las Playas, con 126 casas y 686 habitantes; El Brocal, con 60 casas y 250 habitantes; Santa Isabel, con 108 casas y 622 habitantes, y Santa Teresa, con 90 casas y 373 habitantes. El promedio de casas por comunidad fue de 94 y la población total de 3771 habitantes, de los cuales 1915 fueron del sexo masculino y 1856 del sexo femenino. Mediante un muestreo alterno de las casas se recolectaron muestras de sangre de un total de 2434 personas (1 335 del sexo masculino y 1099 del sexo femenino), que representaron $64,5 \%$ de la población total. En el estudio se incluyeron todas las personas que se encontraban en la casa en el momento de la visita y que dieron su consentimiento para la extracción de una muestra de sangre. En el caso de los niños se les pidió a sus padres el consentimiento por escrito. A todas las personas se les realizó un breve cuestionario para investigar la edad, sexo y antecedentes cardiovasculares de cualquier tipo, prestando especial atención a si habían recibido atención médica y cuál había sido el diagnóstico.

La prueba de ELISA con eluidos de sangre se desarrolló de la forma ya descrita, pero utilizando la dilución óptima previamente establecida en la etapa de estandarización. Para la prueba de IFI se utilizaron epimastigotes de la cepa Y (IOC-106, Rio de Janeiro, Brasil) de T. cruzi provenientes de cultivo, lavados y fijados con formalina según la técnica descrita por Camargo (18). Se utilizó un conjugado anti-IgG humana marcada con fluoresceína (Sigma Chemical Co., Inc., Milwaukee, WI). Todas las preparaciones se examinaron con un microscopio de transmisión de luz ultravioleta (Leitz, Zurich, Switzerland). Inicialmente se examinaron todos los eluidos de sangre tal como se obtuvieron del papel de filtro y los positivos se estudiaron a diluciones dobles desde 1:2 hasta 1:32. Se consideró positivo todo eluido que resultara positivo a diluciones $\geq 1: 2$. Los resultados de los eluidos de sangre estudiados por IFI fueron expresados mediante la media geométrica del título recíproco de anticuerpos, considerándose como título de anticuerpos la máxima dilución con la cual se observaron diferencias entre la fluorescencia del positivo y de los negativos. Se aplicó la $t$ de Student para comparar la media geométrica del título recíproco de anticuerpos obtenida en los seropositivos de cada comunidad. La distribución de la seropositividad mediante ELISA e IFI fue analizada por comunidad, edad y sexo. Se calculó la sensibilidad y especificidad de la prueba de ELISA respecto a la IFI y se calculó la concordancia entre ambas pruebas mediante la $\kappa$ de Cohen.

\section{RESULTADOS}

Después de estudiar por ELISA diferentes diluciones de las muestras de suero total y de eluidos de sangre de los 18 pacientes con enfermedad de Chagas crónica, se obtuvieron valores de absorbencia muy similares con las diluciones de suero a 1:200 (1,55 \pm $0,08)$ y de los eluidos de sangre a $1: 5(1,46 \pm 0,1)$, y también entre las diluciones a 1:400 $(1,42 \pm 0,06)$ y $1: 10$ $(1,3 \pm 0,09), 1: 800(1,19 \pm 0,08)$ y $1: 20$ $(0,99 \pm 0,09)$, y $1: 1600(0,85 \pm 0,09)$ y $1: 40(0,66 \pm 0,08)$. La misma semejanza entre las absorbencias de los sueros y de los eluidos de sangre se observó en los controles negativos a las diluciones de $1: 200(0,33 \pm 0,09)$ y $1: 5(0,27 \pm 0,09)$; $1: 400(0,22 \pm 0,1)$ y $1: 10(0,22 \pm 0,08)$; $1: 800(0,1 \pm 0,07)$ y $1: 20(0,12 \pm 0,09), \mathrm{y}$ $1: 1600(0,09 \pm 0,05)$ y $1: 40(0,66 \pm 0,08)$. Aunque con todas las diluciones estudiadas se obtuvieron diferencias elevadas entre las muestras positivas y negativas $(\mathrm{P} / \mathrm{N})$, se seleccionó como óptima la dilución de 1:20 de los eluidos de sangre (equivalente a 1:800 de los sueros) por ser la que mayor razón $\mathrm{P} / \mathrm{N}$ proporcionó $(8,3)$. Los sueros de los pacientes con enfermedad de Chagas crónica a la dilución de 1:800 mostraron absorbencias que oscilaron entre 0,53 y $1,98(1,2 \pm 0,32)$ y sus eluidos de sangre valores entre 0,68 y 1,3 
$(0,94 \pm 0,16)$. Los sueros de los 30 controles negativos mostraron absorbencias entre 0,06 y $0,43(0,12 \pm 0,11)$ y sus respectivos eluidos valores entre $0,11 \mathrm{y}$ $0,4(0,17 \pm 0,04)$. El límite de positividad establecido para el ensayo, tanto para sueros como para eluidos de sangre, fue de 0,34. Según este criterio, $100 \%$ de los sueros de los pacientes con enfermedad de Chagas crónica resultaron positivos, igual que 3 de los 30 sueros $(10 \%)$ y eluidos de sangre utilizados como controles negativos. La absorbencia de los sueros y eluidos de pacientes con leishmaniasis cutánea osciló entre 0,09 y 0,31 $(0,12 \pm 0,09)$ y 0,09 y $0,29(0,10 \pm 0,09)$, respectivamente, mientras que en los pacientes con leishmaniasis visceral osciló entre 0,44 y $1,2(0,33 \pm 0,31)$ y 0,39 y 0,99 $(0,29 \pm 0,23)$, respectivamente. Tanto para los sueros como para los eluidos de sangre, la prueba presentó una reactividad cruzada de $26,6 \%$, ya que las cuatro muestras de pacientes con leishmaniasis visceral resultaron positivas en el ensayo. La absorbencia media del grupo de pacientes con enfermedad de Chagas crónica presentó diferencias altamente significativas $(P<0,001)$ con respecto al grupo de control negativo y al grupo de pacientes con leishmaniasis cutánea, pero no con respecto al grupo de pacientes con leishmaniasis visceral $(P>0,05)$. La sensibilidad y la especificidad de la prueba de ELISA tanto con muestras de suero como con eluidos de sangre fueron de 100 y $90 \%$, respectivamente. Se obtuvo una buena correlación entre los resultados obtenidos con suero total y con eluidos de sangre $(P<0,001)$, lo cual indica que no existen diferencias en los resultados del diagnóstico atribuibles al tipo de muestra estudiada.

De las 2434 personas estudiadas en la región de Somoto, $260(10,7 \%)$ resultaron positivas por ELISA; $38(14,6 \%)$ pertenecían a la comunidad Aguas Calientes, $27(10,4 \%)$ a La Manzana, 40 $(15,4 \%)$ a Los Canales, $24(9,2 \%)$ a Santa Rosa, $61(23,5 \%)$ a Las Playas, 16 $(6,2 \%)$ a El Brocal, $37(14,2 \%)$ a Santa Isabel y $17(6,5 \%)$ a Santa Teresa. De los 260 seropositivos, 15 (5,8\%) mos- traron absorbencias entre 0,34 y 0,44 $(0,39 \pm 0,09) ; 42(16,2 \%)$ entre $0,45 \mathrm{y}$ $0,59(0,51 \pm 0,09) ; 51(19,6 \%)$ entre $0,6 \mathrm{y}$ $0,79(0,68 \pm 0,11) ; 66(25,4 \%)$ entre $0,8 \mathrm{y}$ $0,99(0,89 \pm 0,1)$ y $86(33 \%)>1,0(1,4 \pm$ $0,13)$. La absorbencia media en las ocho comunidades fue de 0,774 $\pm 0,39$. No se encontraron diferencias significativas en la absorbencia media entre comunidades; sin embargo, en todas las comunidades se encontraron diferencias altamente significativas entre las medias de los seropositivos y los seronegativos $(P<0,001)$. La distribución por sexos mostró que 89 de los $260(34,2 \%)$ seropositivos eran del sexo masculino y $171(65,8 \%)$ del sexo femenino. La distribución de seropositivos por grupos de edad fue la siguiente: $14(5,4 \%)$ casos entre 0 y 10 años, 23 $(8,8 \%)$ entre 11 y 20 años, 26 (10\%) entre 21 y 30 años, $31(11,9 \%)$ entre 31 y 40 años, 55 (21,2\%) entre 41 y 50 años y $111(42,7 \%)$ mayores de 50 años.

Mediante IFI, el número de seropositivos se redujo a $207(8,5 \%)$ : 30 $(14,5 \%)$ de Aguas Calientes, $21(10,1 \%)$ de La Manzana, $31(15,0 \%)$ de Los Canales, $20(9,7 \%)$ de Santa Rosa, 55 $(26,6 \%)$ de Las Playas, 11 (5,3\%) de El Brocal, 29 (14,0\%) de Santa Isabel y 10 $(4,8 \%)$ de Santa Teresa. La media geométrica del título recíproco de anticuerpos de los seropositivos, fue de 85,7 en 59 casos (28,5\%), de 165,3 en 65 $(31,4 \%)$, de 331 en $25(12,1 \%)$ y de 896 en 58 (28,0\%). La media geométrica del título recíproco en las ocho comunidades fue de 562,3. No se encontraron diferencias significativas entre la media geométrica de los títulos en las diferentes comunidades. De los 207 seropositivos, $97(46,9 \%)$ eran del sexo masculino y $110(53,1 \%)$ del sexo femenino. La distribución por grupos de edad fue la siguiente: $9(4,4 \%)$ entre 0 y 10 años, 16 $(7,7 \%)$ entre 11 y 20 años, $19(9,2 \%)$ entre 21 y 30 años, $27(13,0 \%)$ entre 31 y 40 años, 42 (20,3\%) entre 41 y 50 años y $94(45,4 \%)$ mayores de 50 años.

Aunque, tanto por ELISA como por IFI, el mayor número de seropositivos pertenecía al sexo femenino, no se encontró relación significativa entre el número de seropositivos y el sexo. Ninguno de los individuos menores de
50 años refirió síntomas cardiovasculares y solo nueve seropositivos $(8 \%)$ mayores de 50 años refirieron leves episodios de arritmia o taquicardia, sin que para ello procuraran asistencia médica. Ninguna de las personas estudiadas refirió haber padecido leishmaniasis (o lepra de montaña, como es conocida en esta zona); sin embargo, $35,8 \%$ de los individuos afirmaron haber padecido de malaria. Aunque el cuestionario utilizado no incluyó una clasificación de las casas según la calidad de la construcción, de manera general todas podrían haber sido consideradas como regulares o malas, teniendo en cuenta que todas tenían pisos de tierra y paredes y techos de madera, palma o planchas de cinc. Respecto a la IFI, la prueba de ELISA mostró una sensibilidad de $100 \%$ y una especificidad de 97,6\%. La concordancia entre ambas técnicas fue muy elevada $(\kappa=0,96)$. Al relacionar las medias geométricas de los títulos recíprocos de anticuerpos por IFI con las absorbencias obtenidas por ELISA se obtuvo una correlación significativa $(P<0,05)$. Las medias geométricas de 85,7, 165,3, 331 y 896 se correspondían con valores de absorbencia de 0,34-0,59, 0,6-0,79, $0,8-1,0$ y $>1,0$, respectivamente.

\section{DISCUSIÓN}

Las pruebas serológicas constituyen importantes herramientas que permiten estimar los niveles de exposición a T. cruzi en regiones endémicas y muchas han sido utilizadas para evaluar medidas de control en Sudamérica (19, 20). A pesar de los éxitos obtenidos en los programas de control en el Cono Sur, en Centroamérica, y en particular en Nicaragua, aún no se ha puesto en práctica ningún programa de eliminación del vector, debido a que la importancia económica y social de esta enfermedad fue reconocida muy recientemente en la región. Como primer paso para la concepción de un programa de este tipo, el CNDR de Managua, como instituto central de las actividades del Ministerio de Salud, decidió incorporar a su arsenal diag- 
nóstico una técnica altamente sensible con la cual pudiera realizar el diagnóstico individual y acometer estudios poblacionales a gran escala que permitieran estimar la diseminación de la enfermedad de Chagas en el país y, más tarde, evaluar los programas de control. La técnica seleccionada para estos fines fue una prueba de ELISA en fase sólida, que es una de las técnicas serológicas más sensibles utilizadas para el diagnóstico de la enfermedad de Chagas en su fase crónica $(9,10)$.

Teniendo en cuenta que en muchas ocasiones la recolección y transporte de muestras de suero puede constituir una verdadera limitación para la realización de estudios poblacionales, nos propusimos estandarizar el ensayo empleando eluidos de sangre. En un estudio en el que emplearon IFI y HAI con muestras de suero y eluidos de sangre, Zicker et al. obtuvieron resultados significativamente diferentes dependiendo del tipo de muestra (9); sin embargo, en nuestro trabajo, empleando la técnica de ELISA, la concordancia de los resultados obtenidos con sueros y eluidos de sangre fue elevada, y la sensibilidad y especificidad de la prueba fueron comparables a las obtenidas por otros estudios que utilizaron inmunoensayos enzimáticos semejantes (20).

El porcentaje de reacciones cruzadas fue también el esperado, si tenemos en cuenta que T. cruzi y Leishmania spp. poseen múltiples epítopos semejantes localizados en moléculas de glicoproteínas que contienen residuos de galactosa (21), además de proteinas del citoesqueleto, como la tubulina, que son semejantes en muchos tripanosomátidos. Una posible solución para eliminar las reacciones cruzadas es la purificación del extracto soluble para la obtención de antígenos específicos de T. cruzi. Algunos autores $(14,22)$ han señalado que es posible reducir las reacciones cruzadas con Leishmania spp. mediante el empleo en los inmunoensayos enzimáticos de una enzima proteolítica dependiente de cisteína conocida como GP 57/51, presente en las proteínas que liberan los epimastigotes y tripomastigotes de T. cruzi durante la metaciclogénesis (23). Otros informes mencionan la existencia de una glicoproteína de 90 kDa (GP90) que se encuentra en los zimodemas de T. cruzi y que está ausente en los de Leishmania y $T$. rangeli (16). Aunque la utilización de antígenos específicos de T. cruzi sería ideal para eliminar la reactividad cruzada, en el presente estudio esto no fue posible, ya que obtener cualquiera de los antígenos antes mencionados, ya sea por vía recombinante o en forma nativa, requiere recursos y equipamiento cromatográfico hasta el momento inexistentes en las instalaciones del CNDR de Managua. Afortunadamente, en Nicaragua, la enfermedad de Chagas y la leishmaniasis prevalecen en regiones endémicas diferentes, por lo que, aun con el empleo de un extracto soluble no purificado de epimastigotes como el utilizado en este estudio, un resultado positivo en la prueba de ELISA podría sugerir infección por T. cruzi.

La seropositividad global encontrada en este estudio (10,7\%) está en el rango descrito por la OMS (6-30\%) en la zona estudiada (1). Aunque tanto el número de comunidades como el número de personas estudiadas fue elevado, consideramos que estos datos no son representativos de toda la Zona Norte de Nicaragua y que se necesitan estudios epidemiológicos más profundos que aporten datos de seroprevalencia representativos de Somoto y del país. Sin embargo, creemos que las cifras reales no estarán muy lejanas de las encontradas en este estudio, si tenemos en cuenta que el porcentaje global de seropositivos en las ocho comunidades fue muy semejante al descrito en estudios anteriores, con diseño y técnicas serológicas diferentes, realizados en la comunidad de Santa Rosa (24). Una comparación de los resultados de cada una de las comunidades mostró que los porcentajes de seropositividad de Aguas Calientes (14,6\%), La Manzana $(10,4 \%)$, Los Canales $(15,4 \%)$, Santa Rosa $(9,2 \%)$ y Santa Isabel $(14,2 \%)$ eran muy semejantes a los registrados en Guatemala (14\%) y Costa Rica (11\%) (25), mientras que los de otras comunidades, como Las Pla- yas $(23,0 \%)$, eran muy superiores, y los de otras, como El Brocal $(6,2 \%)$ y Santa Teresa $(6,5 \%)$ relativamente bajos. A pesar de estas variaciones de la frecuencia de la seropositividad, no se encontraron diferencias significativas en cuanto al número de positivos por comunidad, lo cual era de esperar debido a que todas poseen las mismas condiciones ecológicas y socioeconómicas. Investigaciones entomológicas aún no publicadas realizadas durante este estudio, demostraron que el vector más frecuentemente encontrado en las viviendas de estas comunidades fue $T$. dimidiata, el cual posee hábitats intradomiciliarios $\mathrm{y}$, aunque es un vector competente de T. cruzi, suele presentar tasas de infección relativamente bajas, a menudo inferiores a 30\%, incluso en adultos (5), y suele estar asociado con un nivel relativamente bajo de infección humana.

En el análisis de la seropositividad según la edad, se obtuvo una curva ascendente que comenzó con un 5,4\% en niños de 0-10 años para llegar a 42,7\% en mayores de 50 años, patrón similar al obtenido en estudios anteriores (24) y típico de zonas endémicas donde la transmisión de $T$. cruzi se mantiene activa y de manera continua durante mucho tiempo. Resulta interesante destacar que ninguno de los individuos seropositivos refirió síntomas clínicos que pudieran relacionarse con la enfermedad de Chagas, lo cual no es de extrañar, debido al largo período asintomático por el que cursa la enfermedad hacia su fase crónica. En un estudio clínico realizado previamente en la comunidad de Santa Rosa (24), también los seropositivos fueron todos asintomáticos, aunque en el examen electrocardiográfico se detectaron diferentes alteraciones, tales como bloqueo auriculoventricular y de la rama izquierda, y bradicardia, que también se observaron en individuos seronegativos. Lamentablemente, en el presente trabajo no se hizo un estudio clínico de los seropositivos, de modo que no pudimos comprobar la presencia de lesiones cardíacas como informaron Zicker et al. (26) en un estudio de casos y controles. 
Aunque el número de seropositivos obtenido por IFI fue inferior al obtenido por ELISA, los resultados de ambas técnicas fueron muy similares en lo que se refiere a la distribución de seropositivos por comunidad, sexo y edad. Además, se detectó una buena correlación entre ambas técnicas al relacionar la media geométrica de los títulos recíprocos de anticuerpos obtenidos por IFI con las absorbencias obtenidas por ELISA. La diferencia en el número de seropositivos con una y otra técnica puede ser atribuida a la mayor sensibilidad y mayor número de verdaderos positivos de la prueba de ELISA en comparación con la IFI (20), pero también podría ser la consecuencia del uso de preparaciones antigénicas diferentes. En la prueba de ELISA se utilizó un extracto crudo donde están representados todos los antígenos solubles que componen el mosaico antigénico del epimastigote, mientras que en la IFI se utilizan parásitos completos donde los únicos antígenos que están disponibles para interactuar con los anticuerpos del huésped son los antígenos de superficie. Es muy posible que en los individuos positivos por ELISA y negativos por IFI predominen anticuerpos estimulados por epitopos antigénicos poco representados en la superficie del epimastigote. Otros autores que utilizaron técnicas serológicas diferentes para detectar la presencia de anticuerpos contra $T$. cruzi obtuvieron también diferencias en el número de seropositivos $(26,27)$. Por otro lado, aunque en este trabajo se utilizó la IFI para evaluar los 2434 eluidos de sangre, debemos reconocer que presenta serias limitaciones de índole práctica que hacen muy difícil su aplicación en estudios poblacionales. La más importante es que solo permite el estudio diario de un limitado número de muestras, por lo que sus resultados son demorados; además requiere un técnico bien adiestrado y un microscopio de fluorescencia que no está al alcance de muchos laboratorios. Por tales razones, en muchas ocasiones se reserva solo para situaciones en las que los resultados obtenidos con otras técnicas serológicas no sean concluyentes.

El presente trabajo permitió aportar nuevos datos al conocimiento de la enfermedad de Chagas en una de las regiones más endémicas de Nicaragua. Debido a que la importancia económica y social de la enfermedad de Chagas fue recientemente reconocida en Centroamérica, en Nicaragua hay un gran interés por conocer la verdadera magnitud de este problema de salud. La prueba de ELISA adaptada al estudio de muestras de sangre recolectadas en papel de filtro permitió detectar un $10.7 \% \%$ de seropositivos al estudiar serológicamente el $64,5 \%$ de la población de ocho comunidades rurales de Somoto. Las cifras de seropositivos obtenidas por IFI fueron ligeramente inferiores (8,5\%). Con ambas técnicas el mayor número de seropositivos se encontró en personas del sexo femenino. Con relación a la edad se observó una curva ascendente donde el mayor número de seropositivos se encontró en personas con más de 50 años. Se encontró una buena correlación entre los títulos de anticuerpos medidos por IFI y los valores de ab- sorbencia obtenidos por ELISA. La prueba de ELISA proporcionó una sensibilidad de $100 \%$ y una especificidad de $97,6 \%$ respecto a la IFI. Aunque el antígeno utilizado en la prueba de ELISA fue un extracto soluble no purificado, solo se observaron reacciones cruzadas con muestras de pacientes con leishmaniasis visceral. Al estudiar en paralelo 18 muestras de suero y de eluidos de sangre de pacientes con enfermedad de Chagas crónica y de 30 controles negativos, se obtuvieron resultados muy semejantes que demostraron la factibilidad de utilizar muestras de sangre recolectadas en papel de filtro, sin que ello implicara diferencias significativas en los resultados. En un futuro cercano, el CNDR de Managua se propone aplicar esta técnica en un estudio de seroprevalencia nacional, con el propósito de conocer el verdadero estado de la enfermedad de Chagas en el país y propiciar posteriormente la aplicación de programas de control antivectorial.

Agradecimientos. Esta investigación contó con el respaldo económico de la OMS y el Programa de Cooperación Técnica entre Países en Desarrollo de la OPS. Los autores agradecen al Dr. Alcides González, Director del Centro Nacional de Diagnóstico y Referencia de Managua, el apoyo brindado a esta investigación, a la dirección de Entomología de este centro su ayuda en la recolección de muestras de sangre, y al Dr. Esteban Alberti, del Instituto de Medicina Tropical "Pedro Kourí" de La Habana, su gentileza al aportar parte de los antígenos utilizados.

\section{REFERENCIAS}

1. World Health Organization. Control of Chagas disease: report of a WHO expert committee. Geneva: WHO; 1991. pp. 1-4. (Technical Report series 811).

2. Organización Panamericana de la Salud/ Organización Mundial de la Salud. La Salud en Las Américas. Washington D.C.: OPS/ OMS; 1998. pp. 1-14 (Publicación Científica No. 569).
3. Gasteazoro R, Montes A. Estudio seroepidemiológico y clínico de la enfermedad de Chagas en San Francisco, Matagalpa, Nicaragua [tesis doctoral]. Managua: Universidad Nacional Autónoma de Nicaragua; 1992.

4. Siva S and Gómez M. Aspectos epidemiológicos de la enfermedad de Chagas en la comunidad El Eden, Ticuantepe, Managua [tesis doctoral]. Managua: Universidad Nacional Autónoma de Nicaragua; 1990.

5. Schofield CJ, Dujardin JP. Chagas disease vector control in Central América. Parasitol Today 1997;13:141-144.

6. Zeledón R, Rabinovich JE. Chagas' disease: an ecological appraisal with special emphasis on its insect vectors. Annu Rev Entomol 1981;26: 101-133. 
7. Schmunis GA, Zicker F, Pinheiro F, Brandling-Bennett D. Risk for transfusiontransmitted infectious diseases in Central and South America. Emerg Infect Dis 1998;4:5-11.

8. Botero D, Restrepo M. Parasitosis humanas. Tripanosomiasis. Cap. 17. 2a. ed. Medellín: Corporación para las Investigaciones Biológicas; 1994. p. 191.

9. Zicker F, Smith PG, Luquetti AO, Oliveira OS. Detección de infectados por Trypanosoma cruzi mediante inmunofluorescencia, ELISA y hemaglutinación en suero y eluidos de sangre seca. Bol Of Sanit Panam 1991;110: 489-496.

10. Cuna WR, Rodríguez C, Torrico F, Afchian D, Loyens M, Desjeux P. Evaluation of a competitive enzyme immunoassay for specific diagnosis of Chagas' disease. J Parasitol 1989;75: 357-359.

11. Gazzinelli RT, Galvao LM, Cardoso JE, Cancado JR, Kretti AU, Brener Z, et al. Anti-Trypanosoma cruzi and anti-laminin antibodies in chagasic patients after specific treatment. J Clin Microbiol 1988;26:1795-1800.

12. Umekita LF, Ramos DP, Barbaru KC, Mota J. Biological activity of chronic phase antibodies eluted from sensitized Trypanosoma cruzi trypomastigotes. Immunol Lett 1999;70:73-76.

13. Urroz C, Espinoza H. Situación actual de los conocimientos sobre la enfermedad de Chagas en Nicaragua. En: III Congreso Centroamericano de Microbiología. Guatemala, 1971. Resúmenes.

14. Alberti E, Fachado A, Montalvo AM, Izquierdo LA, Fonte L. Proteasa dependiente de cisteina en Trypanosoma cruzi útil en el diagnóstico de la enfermedad de Chagas. Rev Cub Med Trop 1998;50:75-81.
15. Nilsson LA, Voller A. A comparison of thin layer immunoassay (TIA) and enzyme-linked immunosorbent assay (ELISA) for the detection of antibodies to Trypanosoma cruzi. Trans R Soc Trop Med Hyg 1982;76:95-97.

16. Schechter M, Flint JE, Voller A, Guhl F, Marinkele CJ, Miles MA. Purified Trypanosoma cruzi specific glycoprotein for discriminative serological diagnosis of South American trypanosomiasis (Chagas' disease) Lancet 1983;2(8356):939-941.

17. Souza SL, Camargo ME. The use of filter paper blood smears in a practical fluorescent test for American Trypanosomiasis serodiagnosis. Rev Inst Med Trop São Paulo 1966;8: 255-258.

18. Camargo ME. Fluorescent antibody test for the serodiagnosis of American trypanosomiasis. Technical modification employing preserved culture forms of Trypanosoma cruzi in a slide test. Rev Inst Med Trop São Paulo 1966; 8:227-234.

19. Segura EL, Perez AC, Yanovsky JF, Andrade J, de Martini GJ. Decrease in the prevalence of infection by Trypanosoma cruzi (Chagas' disease) in young men of Argentina. Bull Pan Am Health Organ, 1985;19:252-264.

20. Figueredo-Silva J, Kaneda $\mathrm{Y}$, Tachibana $\mathrm{H}_{t}$ Furushima R, Tateno S, Correia-Lima FG, et al. Epidemiological survey of Trypanosoma cruzi infection in north-eastern Brazil using different diagnostic methods. Rev Med Inst Trop São Paulo 1991;33:193-198.

21. Avila JL, Rojas M. A galactosyl( $\alpha 1-3)$ mannose epitope on phospholipids of Leishmania mexicana and L. braziliensis is recognized by trypanosomatid-infected human sera. J Clin Microbiol 1990;28:1530-1537.
22. Gazzineli RT, Galvão LM, Krautz G, Lima PC, Cancado JR, Scharfstein J, et al. Use of Trypanosoma cruzi purified glycoprotein (GP57/ 51) or trypomastigote-shed antigen to assess cure for human Chagas' disease. Am J Trop Med Hyg 1993;49:625-635.

23. Bonaldo MC, D'Escoffier LN, Salles JM, Goldenberg S. Characterization and expression of proteases during Trypanosoma cruzi metacyclogenesis. Exp Parasitol 1991;73:44-51.

24. Rivera T, Palma-Guzman R, Morales W. Seroepidemiological and clinical study of Chagas' disease in Nicaragua. Rev Inst Med Trop São Paulo 1995;37:207-213.

25. Zeledón R. Los vectores de la enfermedad de Chagas en América. In: Simposio Internacional sobre la enfermedad de Chagas. Buenos Aires, Sociedad Argentina de Parasitología 1972, pp. 327-345.

26. Fuchs AP, Fioratti VL, de Mello VA, Boainain E. Diagnóstico serológico na doença de Chagas. Estudo comparativo de diferentes técnicas. Rev Inst Med Trop São Paulo 1980;22: 242-245.

27. Camargo ME, Segura EL, Kagan IG, Souza JM, Carvalheiro JR, Yanovsky JF, et al. Normalización del diagnóstico serológico de la enfermedad de Chagas en las Américas: evaluación de 3 años de colaboración. Bol Of Sanit Panam 1987;102:449-463.

Manuscrito recibido el 10 de noviembre de 1999 y aceptado para publicación, tras revisión, el 16 de mayo de 2000
ABSTRACT

Trypanosoma cruzi antibody detection in eight rural communities of Somoto, Nicaragua, through indirect ELISA and indirect immunofluorescence in blood samples collected on filter paper
We standardized a solid-phase enzyme-linked immunosorbent assay (ELISA) in order to study the presence of Trypanosoma cruzi antibodies in asymptomatic persons who live in an area of Nicaragua endemic for Chagas' disease. The test was standardized to analyze filter-paper blood samples, which are easy to transport. In the first phase of our investigation, ELISA was used to study 18 samples of total serum and 18 eluates of blood from patients with chronic Chagas' disease; 30 samples of serum and 30 eluates of blood from healthy people, used as negative controls; and 14 samples of serum and 14 eluates of blood from patients with cutaneous or visceral leishmaniasis, which were used to study cross-reactions. Both with the total-serum and the blood-eluate samples, the ELISA test provided $100 \%$ sensitivity and $90 \%$ specificity. Cross-reactions in the patient samples were observed only with visceral leishmaniasis. The second phase of our investigation was a population study that included eight rural communities in the area of Somoto, Nicaragua. Through random sampling, filter-paper blood samples were collected from 2434 people (1 335 men and 1099 women) from the communities of Aguas Calientes, El Brocal, La Manzana, Las Playas, Los Canales, Santa Isabel, Santa Rosa, and Santa Teresa. Studied by ELISA and by indirect immunofluorescence (IIF), the samples included 260 found seropositive by ELISA (10.7\%), of which 207 were positive according to IIF (8.5\%). With both techniques, the majority of seropositives were among women, but the difference between men and women was not statistically significant. There was a high level of agreement between the results obtained with the two techniques. There was an upward trend with age, with $5.4 \%$ of those found seropositive by ELISA being persons 10 years of age or younger and $42.7 \%$ of those found seropositive being older than 50 . The vast majority of the individuals analyzed were asymptomatic. 